TẠP CHÍ KHOA HỌC ĐẠI HỌC ĐÀ LẠT Tập 9, Số 3, 2019 7-16

\title{
KỸ NGHỆ SƠ KỲ ĐÁ CŨ AN KHÊ Ở VIÊTT NAM VỚI CÁI GỌI LÀ CON ĐƯờNG MOVIUS
}

\author{
Nguyễn Khắc Sử ${ }^{2^{*}}$ \\ ${ }^{a}$ Viện Khảo cổ học Việt Nam, Hà Nội, Việt Nam \\ *Tác giả liên hệ: Email: khacsukc@gmail.com \\ Lịch sử bài báo \\ Nhận ngày 12 tháng 03 năm 2019
}

Chỉnh sửa ngày 20 tháng 04 năm 2019 | Chấp nhận đăng ngày 01 tháng 08 năm 2019

\section{Tóm tắt}

Tù̀ năm 2014 đến 2019, các nhà khảo cổ học Việt - Nga đã khai quật bốn trong 23 địa điểm so kỳ Đá cũ ở thị xã An Khê, tỉnh Gia Lai. Kỹ nghệ An Khê đuợc đặc trung bởi tổ hợp công cu cuọi quartz, quartzite, kích thước lớn, ghè đẽo thô so. Về loại hình hoc, phức hợp công cu gồm ghè hai mặt/riu tay, mũi nhọn/ mũi nhọn tam diện, và

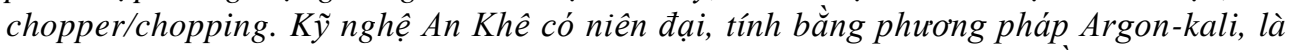
$806,000 \pm 22,000 B P$ và 782,000 $\pm 20,000 B P$. Kỹ nghệ An Khê tuơng đồng với kỹ nghệ so kỳ Đá cũ Bách Sắc (Trung Quốc) cả về chẩt liệu, kỹ thuật và hình dáng công cụ. Các phát hiện khảo cổ học ở Việt Nam và Trung Quốc cho thấy, các công cu ghè hai mặt cùng xuất hiện tù̀ so kỳ Đá cũ. Sẽ là sai lầm khi cho rằng, nhũng nguời chế tao rìu tay là đại diện cho khu vực năng động, tiên tiến, còn nhũng nguời chế tác chopper/choping lại là người bảo thủ và lạc hậu.

Từ khóa: Chopper; Đá cũ; Kỹ nghệ; Rìu tay.

DOI: http://dx.doi.org/10.37569/DalatUniversity.9.3.548(2019)

Loại bài báo: Bài báo nghiên cứu gốc có bình duyệt

Bản quyền (C) 2019 (Các) Tác giả.

Cấp phép: Bài báo này được cấp phép theo CC BY-NC-ND 4.0 


\title{
THE LOWER PALEOLITHIC INDUSTRY OF ANKHE IN VIETNAM WITH THE SO-CALLED MOVIUS LINE
}

\author{
Nguyen Khac Su${ }^{\mathrm{a}^{*}}$ \\ ${ }^{a}$ The Institute of Archaeology, Hanoi, Vietnam \\ ${ }^{*}$ Corresponding author: Email: khacsukc@gmail.com
}

Article history

Received: March $12^{\text {th }}, 2019$

Received in revised form: April 20 ${ }^{\text {th }}, 2019 \mid$ Accepted: August $1^{\text {st }}, 2019$

\begin{abstract}
From 2014 to 2019, four of 23 Lower Paleolithic sites were excavated by a joint Vietnamese - Russian team of archaeologists in Ankhe town, Gialai province. The An Khe industry is characterized by a collection of stone tools made of local river and stream quartz, quartzite pebbles which are large, hard, and fine grained. Typologically, the representative tools are a complex of bifacial tools/handaxes, picks/triangular-sectioned picks, and choppers/chopping tools. The An Khe industry is dated by the K-Ar isotope method resulting in dates of $806,000 \pm 22,000 \mathrm{BP}$ and 782,000 $\pm 20,000 \mathrm{BP}$. The An Khe industry has similar characteristics in terms of material, technique, type, and date to the Baisei (China) industry. The archaeological discoveries in Vietnam and China show that bifaces appear from the Early Paleolithic. It would be a serious mistake to argue that those who manufactured handaxes represented a dynamic and advanced area, while the others who produced choppers/chopping tools represented a conservative and backward one.
\end{abstract}

Keywords: Chopper; Hand ax; Industry; Old stone.

DOI: http://dx.doi.org/10.37569/DalatUniversity.9.3.548(2019)

Article type: (peer-reviewed) Full-length research article

Copyright $(0) 2019$ The author(s).

Licensing: This article is licensed under a CC BY-NC-ND 4.0 


\section{Kर̃ NGHỆ AN KHÊ}

1.1. Năm 2014, triển khai nhiệm vụ cấp Bộ "Điều tra khảo sát các di tích tiền sư ở khu vục thượng du sông $B a$ " do Viện Khảo cổ học chủ trì, cán bộ Viện Khảo cổ học Việt Nam đã phát hiện năm địa điểm Đá cũ ở thị xã An Khê, tỉnh Gia Lai (Nguyễn \& Nguyễn, 2015, tr. 7-19). Trong các năm 2015 đến 2019, khi triển khai chương trình hợp tác nghiên cứu khảo cổ học Việt - Nga, đoàn công tác Viện Khảo cổ học Việt Nam, Sở Văn hóa Thể thao và Du lịch tỉnh Gia Lai và Viện Khảo cổ học - Dân tộc học Novosibirsk thuộc Viện Hàn lâm khoa học Liên bang Nga đã phát hiện mới 19 địa điểm, trong đó bốn địa điểm đã được khai quật là Gò Đá, Rộc Tưng 1, Rộc Tưng 4 và Rộc Tưng 7 (Hình 1).

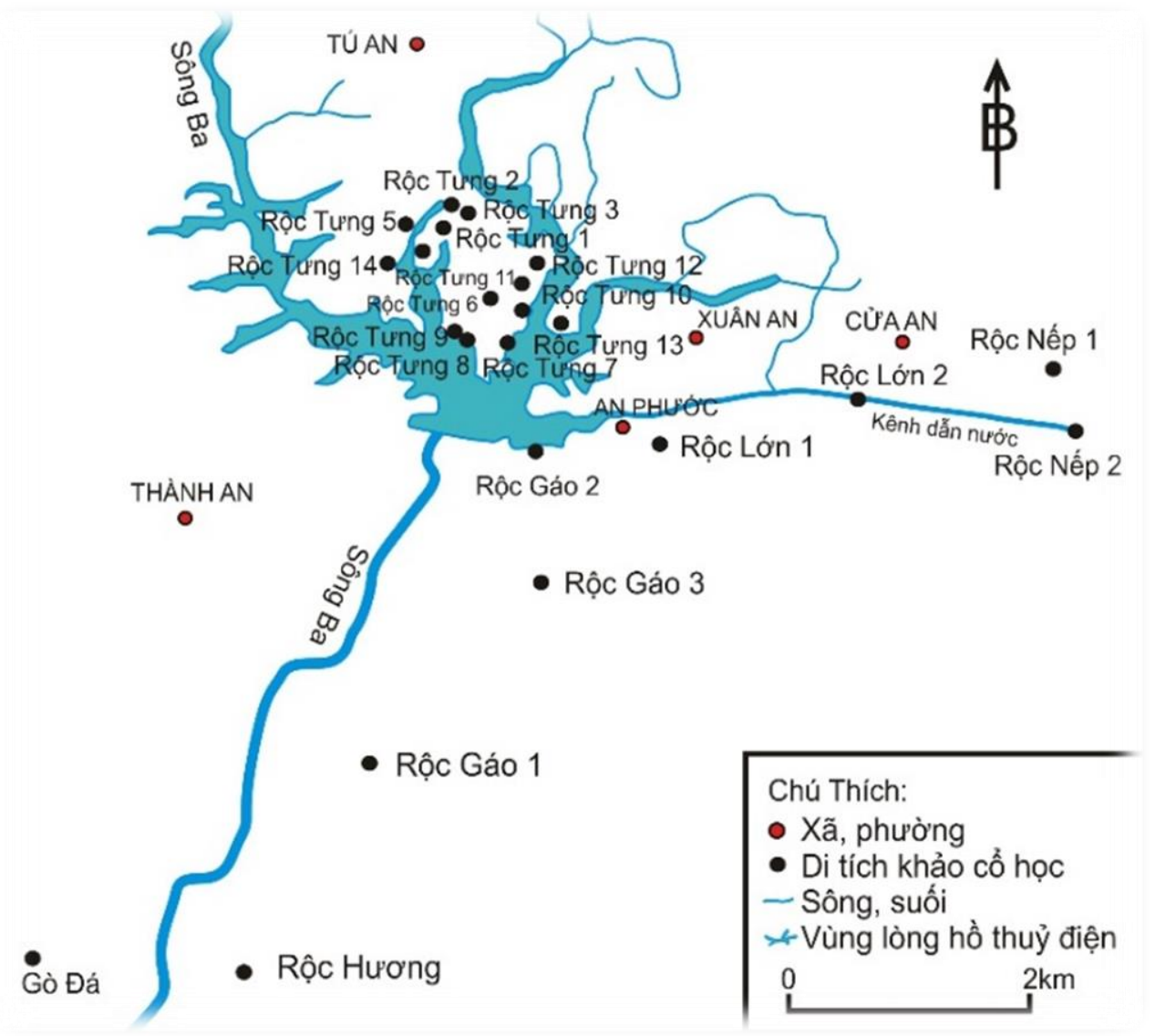

\section{Hình 1. Các di tích sơ kỳ Đá cũ ở An Khê, tỉnh Gia Lai}

Nguồn: Nguyễn (2017).

Trong các di tích trên đã thu được hàng ngàn hiện vật đá và hàng trăm mảnh tectits (thiên thạch). Những kết quả nghiên cứu các di tích này đã được trình bày trong Hội thảo quốc tế lần thứ nhất tháng 11/2016 và lần thứ hai tháng 03/2019 cùng một số bài báo khác (Derevianko, Nguyen, Tsybankov, \& Nguyen, 2016). Đây là nguồn sử liệu quan trọng trong nghiên cứu giai đoạn tiền sử Việt Nam và Đông Nam Á giai đoạn sơ kỳ Đá cũ. 
1.2. Các di tích khảo cổ ở An Khê phân bố trên các đồi gò cao trung bình từ $420 \mathrm{~m}$ đến $450 \mathrm{~m}$ so với mực nước biển. Đây là vùng chuyển tiếp từ cao nguyên xuống vùng đồng bằng ven biển miền Trung Việt Nam. Địa hình nơi đây khá bằng phẳng, với hệ động vật và thực vật phong phú, đa dạng; Có nguồn nguyên liệu đá cuội dồi dào nên rất thích hợp cho người tiền sử chế tác công cụ và cư trú lâu dài.

Địa tầng của di tích bảo lưu dấu vết văn hóa của người tiền sử vùng An Khê, dày trung bình từ $25 \mathrm{~cm}$ đến $40 \mathrm{~cm}$, nằm ngay dưới lớp đất canh tác và nằm trên lớp đất đá granit (Hình 2). Chúng là sản phẩm phong hóa tại chỗ của đá granit và đã bị laterit hóa với độ gắn kết rắn chắc. Trong địa tầng đã tìm thấy công cụ lao động của con người và những mảnh tectits có cạnh mỏng sắc bị vỡ khi rơi từ ngoài hành tinh vào. Địa tầng chứa di tồn văn hóa của con người ở An Khê khá nguyên vẹn (insitu).

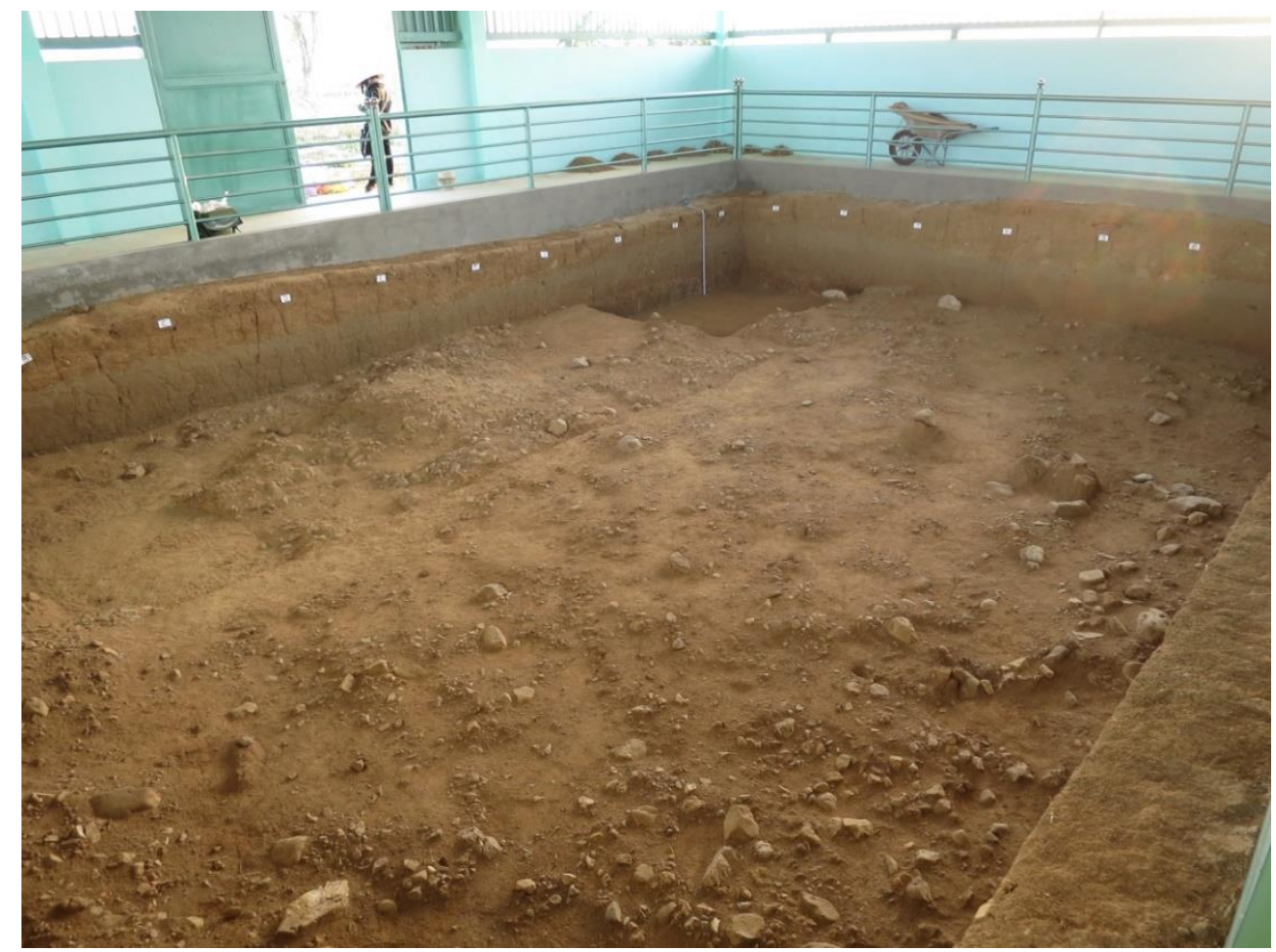

Hình 2. Mặt bằng bảo tồn ở địa điểm Rộc Tùng 1 (An Khê)

Nguồn: Nguyễn (2017).

1.3. Tổ hợp hiện vật thu được trong các cuộc khai quật ở An Khê có sự thống nhất, ổn định về chất liệu, loại hình, kỹ thuật chế tác và mang đặc trưng chung của một kỹ nghệ sơ kỳ Đá cũ, mang tên kỹ nghệ An Khê.

Kỹ nghệ An Khê được đặc trưng bởi tổ hợp công cụ đá làm từ cuội sông suối tại địa phương có kích thước lớn. Kết cẩu đá cứng, hạt mịn, chủ yếu là đá thạch anh (quartz), thạch anh biến tính (quartzite) và đá sét silic. Trên thân công cụ còn bảo lưu kỹ thuật ghè đẽo thô sơ của con người, hầu như ít được tu chỉnh. Loại hình công cụ tiêu biểu là phức hợp, như: Công cụ ghè hai mặt/rìu tay (handaxe), mũi nhọn - mũi nhọn tam diện (triangle shaped cross-section pick), và công cụ chặt thô (chopper, choping - tool). 
- Rìu tay (Hand axes): Có mặt trong một số địa điểm Đá cũ An Khê với số lượng không nhiều. Trong đó có ba chiếc ở Gò Đá, bốn chiếc còn lại ở Rộc Lớn, Rộc Gáo, Rộc Hương, và Rộc Tưng, mỗi nơi một chiếc. Chúng được làm từ đá cuội quartzite, thân hình mũi lao (Lanceate) với một đầu thuôn nhọn và đốc cầm tròn. Các vết ghè tập trung ở $2 / 3$ thân kể từ đầu nhọn, ghè hai mặt, vết ghè nhỏ đan nhau; hướng ghè từ rìa vào trung tâm để tạo ra một đường nổi cao chạy từ đầu nhọn đến gần đốc cầm nên công cụ có hình dáng dày ở giữa và mỏng dần về hai rìa. Rìu tay ở An Khê có kích thước lớn, trung bình: Dài $20.7 \mathrm{~cm}$, rộng $11.9 \mathrm{~cm}$, dày $7.4 \mathrm{~cm}$, và nặng $1.9 \mathrm{~kg}$ (Hình $3 \mathrm{a}$ và $3 d$ ).

- Mũi nhọn (Pick): Chiếm số lượng lớn trong kỹ nghệ An Khê, trong đó loại thân mỏng có 67 chiếc và loại thân hình khối tam diện có 15 chiếc. Mũi nhọn tam diện có ba mặt phẳng kẹp một đầu nhọn; Các công cụ được làm từ cuội quartzite, kích thước lớn. Một số tận dụng hai mặt phẳng tự nhiên giao nhau thành một góc tù, chỉ cần ghè thêm một mặt phẳng nữa là hoàn thiện. Với những viên cuội có một mặt phẳng tự nhiên, thì người xưa sẽ ghè thêm hai mặt phẳng nữa. Các vết ghè trên thân thường nhỏ, đều đặn và ghè hướng tâm, tạo ra một đầu nhọn với mặt cắt ngang hình tam giác và một đốc cầm to. Kích thước trung bình: Thân dài $19.8 \mathrm{~cm}$, rộng $11.9 \mathrm{~cm}$, thân dày $8.07 \mathrm{~cm}$, và nặng $2.32 \mathrm{~kg}$.

- Chopper: Có 26 chiếc, được chế tác từ những viên cuội quartz hoặc quartzite, kích thước lớn, có thân hình bầu dục, và vết ghè tập trung ở một dầu hẹp của viên cuội tạo rìa lưỡi. Những tiêu bản ghè một mặt, từ mặt cuội này sang mặt kia tạo ra chopper, còn vết ghè hai mặt tạo ra chopping - tool. Công cụ có một rìa lưỡi sắc và một cầm còn vỏ cuội. Trên thân của công cụ còn giữ lại tối đa vỏ cuội tự nhiên. Kích thước trung bình: Thân dài $19.2 \mathrm{~cm}$, rộng $11.7 \mathrm{~cm}$, dày $9.0 \mathrm{~m}$, và trọng lượng là $2.4 \mathrm{~kg}$.

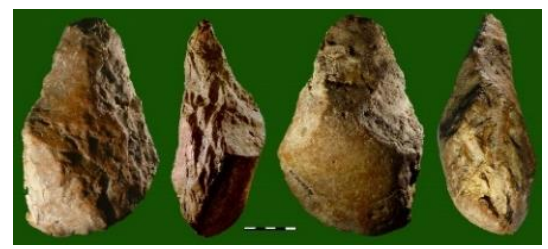

(a)

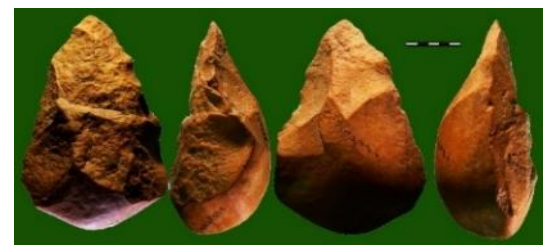

(c)

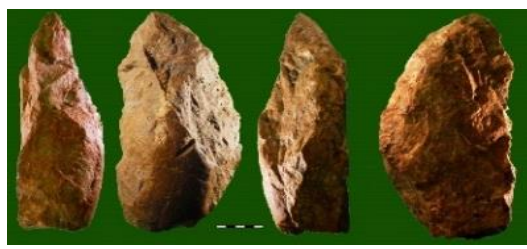

(b)

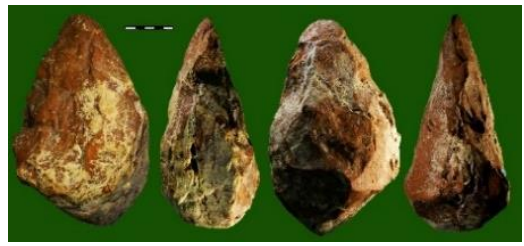

(d)

Hình 3. Rìu tay trong kỹ nghệ sơ kỳ Đá cũ An Khê

Ghi chú: a) Gò Đá; b) Rộc Tưng; c) Rộc Gáo; và d) Rộc Lớn.

Nguồn: Derevianko et al. (2016). 
Ngoài ra, trong kỹ nghệ An Khê còn có công cụ ghè hết một mặt (unifacial tool), dao, nạo, hòn ghè, hạch đá và công cụ mảnh tước, hay cuội có vết ghè đẽo. Kỹ nghệ sơ kỳ Đá cũ An Khê được xác định niên đại tuyệt đối bằng phương pháp Kalium - Argon (K/Ar) trên hai mẫu tectits lấy từ Phòng Thí nghiệm Đồng vị Địa hóa học và Địa thời học (IGEM RAN) của Viện Hàn lâm Khoa học Nga, cho kết quả: Mẫu ký hiệu 15.GD.M4.L1-2 ở địa điểm Gò Đá là 806,000 \pm 22,000BP và mẫu ký hiệu 16.RT1. H1.F6.L2.2 Rộc Tưng là 782,000 \pm 20,000BP (Nguyễn, 2017).

\section{CON ĐƯỜNG MOVIUS}

Movius (1948), một giáo sư tại Đại học Harvard đã đưa ra một giả thuyết về sự tồn tại của hai vùng văn hóa và lịch sử lớn ở lục địa Âu - Á, có niên đại sơ kỳ Đá cũ (Lower Paleolithic). Mỗi vùng được đặc trưng bởi một loại hình công cụ bằng đá: Các công cụ chopper - choppings đại diện cho vùng Đông, Nam, và Đông Nam Á, còn rìu tay đại diện cho châu Âu và châu Phi (Movius, 1948, tr. 330-420).

Trong 70 năm qua, hàng trăm di tích sơ kỳ Đá cũ đã được phát hiện và nghiên cứu ở Đông và Đông Nam Á đã cung cấp nhiều bằng chứng mới cho việc đánh giá vị trí của các kỹ nghệ công cụ bằng đá ở miền Đông của lục địa Âu - Á. Trong giai đoạn này, các nhà nghiên cứu liên tục phân tích các khía cạnh khác nhau của cái gọi là Con đường Movius (Movius Line), một vấn đề liên quan đến cả hai vùng Âu - Ả được thảo luận trong các hội nghị chuyên đề khoa học quốc tế, cũng như các bài báo khoa học khác.

Một trong những cuộc thảo luận có ý nghĩa đầu tiên là sau khi công bố bài báo của Seonbok \& Clark trong Nhân loại học hiện đại. Cuộc tranh luận này, giống như nhiều người khác, chủ yếu tập trung vào việc chỉ trích giả thuyết của Movius. Trong các cuộc thảo luận, bằng chứng không thể chối cãi được là sự tồn tại đồng thời cả hai loại hình công cụ: Chopper / choping-tool và công cụ ghè hai mặt (bifaces) trong sơ kỳ thời đại Đá cũ ở Đông và Đông Nam Á đã được trình bày. Một thời gian sau đó, có hàng trăm bài báo khác cũng đã được công bố, cung cấp nhiều hơn nữa tư liệu mới xác nhận sự hiện diện của các công cụ đá được ghè hai mặt, đặc biệt là rìu tay (Handaxes) tại các di tích sơ kỳ Đá cũ ở phía đông lục địa Âu - Á.

Thật ra, lúc đầu Movius (1948) cũng đã nhận ra sự hiện diện của kỹ nghệ ghè hai mặt với rìu tay và chopping tools ở Đông Nam Á trong kỹ nghệ sơ kỳ Đá cũ Patjitanian (Movius, 1949). Ông cũng là người nói đến sự hiện diện của các công cụ ghè hai mặt (biface) trong kỹ nghệ ở Đinh Thôn (Dingcun), Trung Quốc (Movius, 1956, tr. 13-26). Tuy nhiên, ông là người đầu tiên phân biệt sự khác nhau giữa các tập hợp đá cũ ở Đông Nam Á và Đông Á và những phần còn lại của lục địa Á - Âu (Movius, 1958, tr. 351-355).

Ở Trung Quốc, một trong những địa điểm sơ kỳ Đá cũ sớm nhất, phát hiện công cụ biface rõ ràng đó là di tích ở Huyện Vân (Yunxian) thuộc tỉnh Hồ Bắc, ở phía thượng lưu sông Hán Thủy (Han Shui), và ở phía tây bắc của tỉnh Hà Bắc (Hubei). Trong kỹ nghệ Huyện Vân, công cụ bằng đá như những mũi nhọn (picks) và bifaces đã chứng 
minh được sự có mặt của chúng có niên đại rất sớm. Tuổi của các trầm tích chứa các lớp văn hóa với các hiện vật ghè hai mặt ước tính khoảng một triệu năm cách ngày nay.

Số lượng công cụ bifaces lớn nhất được phát hiện ở thung lũng Bách Sắc (Base), tỉnh Quảng Tây, Trung Quốc. Hơn 30 năm nghiên cứu khảo cổ, với trên 40 địa điểm, đã thu được khoảng 7,000 hiện vật đá nằm rải rác trên bề mặt, bao gồm cả các mảnh đá ghè hai mặt có dấu sử dụng, đã được tìm thấy trong thung lũng Bách Sắc (Guangmao, 2002, tr. 65-73). Kỹ nghệ Bách Sắc có tuổi 733,000 \pm 39,000BP đã được xác định niên đại bằng phương pháp đồng vị phóng xạ (Gao, Huang, Hao, \& Chen, 1997, tr. 565-570) và bằng phương pháp Kalium - Argon (39Ar/40Ar) cho kết quả là 803,000 $\pm 3,000 \mathrm{BP}$ (Yiamei \& ctg., 2000, tr. 1622-1626).Với niên đại này, Bách Sắc được xem là đại diện cho kỹ nghệ có rìu tay sơ kỳ Đá cũ tiêu biểu của vùng Đông Á (Guangmao, 2007, pp. 182-206).
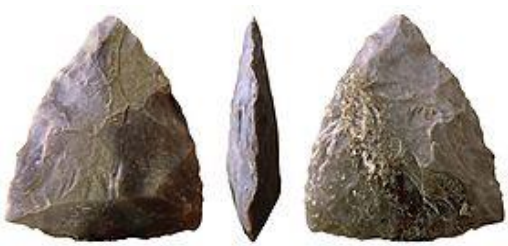

(a)
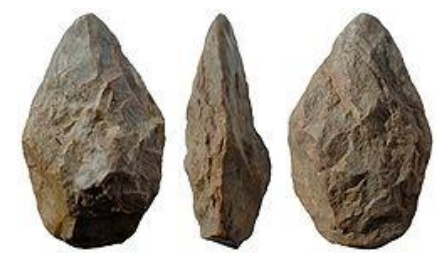

(c)
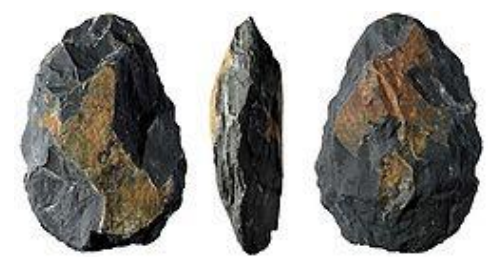

(e)

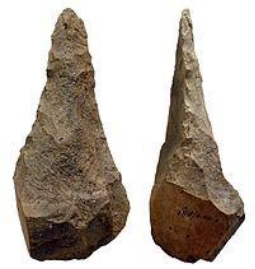

(g)
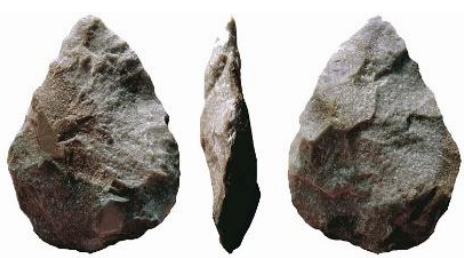

(b)
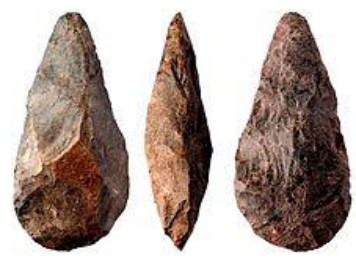

(d)
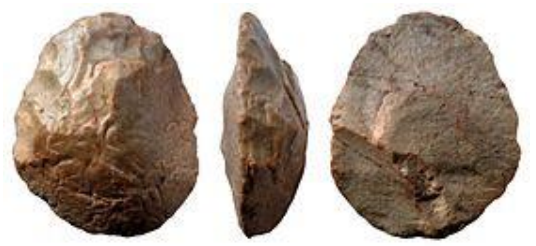

(f)
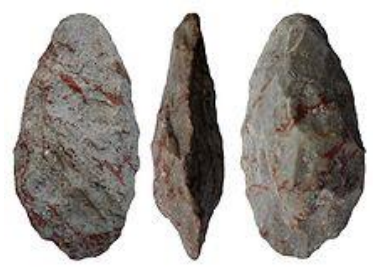

(h)

\section{Hình 4. Các loại rìu tay trong kỹ nghệ Acheulean}

Ghi chú: a) Hình tam giác (triangular); b) Hình trái tim (cordiform); c) Hình quả hạnh nhân (Amygdaloidal); d) Hình mũi lao (Lanceate); e) Hình trứng (Ovoid); f) Hình đĩa (Discoid);

g) Hình micoqui (Micoquien); và h) Hình Elip (Ellipical).

Nguồn: Balout (1967). 
Trong kỹ nghệ sơ kỳ Đá cũ An Khê ở Việt Nam cũng đã xác nhận sự hiện diện của kỹ nghệ ghè hai mặt, trong đó có rìu tay. Rìu tay ở An Khê khác với kỹ nghệ Acheulean ở châu Âu, nơi rìu tay là công cụ tiêu biểu nhất, chúng được làm từ đá lửa (flint); Các công cụ này được ghè hai mặt, có một rìa lưỡi mỏng nhọn, đốc cầm rộng và dày, và thân bằng, đặc trưng cho sơ kỳ Đá cũ châu Âu. Rìu tay ở đây có các hình dáng khác nhau: Hình tam giác, hình trái tim, hình quả hạnh nhân, hình mũi lao, hình trứng, hình đĩa, hình elíp... tiêu biểu nhất là loại có hình mũi lao (Hình 4) (Balout, 1967, pp. 701-735).

Kỹ nghệ An Khê (Việt Nam) và kỹ nghệ Bách Sắc (Trung Quốc) đều thuộc kỹ nghệ công cụ cuội (Pebble-tool industry), có nét tương đồng nhất định về chất liệu, kỹ thuật và loại hình công cụ hạch cuội, nhất là rìu tay. Mảnh tước ở cả hai bên đều không đặc trưng cho kỹ thuật Clacton hay Levallois như châu Âu. Giữa hai nơi có sự khác biệt nhất định về công cụ mũi nhọn (pick). Nếu như công cụ mũi nhọn ở Bách Sắc có thân mỏng, mặt lưng cong lồi còn giữ nguyên vỏ cuội, khiến đầu nhọn hơi cong hất lên so với trục thân; Hình dáng này thuận tiện cho chức năng đào và móc đất. Ngược lại, ở An Khê mũi nhọn lại có hình khối tam diện, mặt cắt ngang hình tam giác, và đầu nhọn rơi vào giữa tâm mặt cắt ngang, thích hợp cho chức năng chặt và xẻ thịt động vật lớn có bộ da rất dày như voi, trâu bò ràng.

Những công cụ ghè hết hay gần hết một mặt ở An Khê có tỷ lệ cao hơn so với loại hình cùng loại ở Bách Sắc. Ngược lại di vật kiểu bôn tay (cleaver-like artifacts) ở Bách Sắc trội hơn hẳn so với An Khê. Dẩu khác nhau mang tính tiểu dị, song cả hai đều tồn tại công cụ ghè hai mặt/rìu tay, thật sự là đại diện cho kỹ nghệ ghè hai mặt sớm ở khu vực Đông Nam Á và Đông Á, với niên đại từ 700,000 - 800,000BP (Nguyen, 2017, pp. 13-25) (Hình 5).
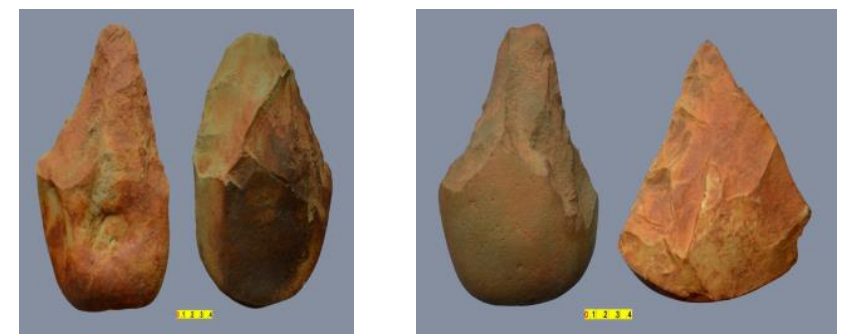

\section{Hình 5. Rìu tay Bách Sắc (Quảng Tây, Trung Quốc)}

Nguồn: Phan (2017).

\section{KẾT LUẬn}

Kết quả nghiên cứu các di tích và di vật giai đoạn sơ kỳ Đá cũ ở An Khê (Gia Lai), chúng tôi cho rằng, tất cả các công cụ ghè hai mặt (bifaces), trong đó có rìu tay (Handaxes) ở các di tích sơ kỳ Đá cũ ở Nam Trung Quốc và Việt Nam là một thành tố trong tổ hợp công cụ đá của người nguyên thủy, giai đoạn Homo erectus. Những rìu tay này đã thể hiện được những khác biệt đáng kể so với bifaces Acheulian, trong khung thời gian từ $1,000,000-300,000 \mathrm{BP}$. 
Và như vậy, ngay từ đầu đã không có sự đối lập tuyệt đối giữa phương Đông: Chuyên chế tác chopper hay chopping; Còn phương Tây: Chuyên chế tác rìu tay. Sự khác nhau về loại hình học công cụ phương Tây chủ yếu gặp bifaces hay handaxes, còn ở châu Á chủ yểu là chopper hay chopping là do sự tương thích của con người tiền sử với môi trường tự nhiên, trong đó có vấn đề nguồn nguyên liệu đá sử dụng chế tác công cụ và nhu cầu chế tác loại công cụ phục vụ trong các hoạt động săn bắt và hái lượm kiếm sống của con người thời nguyên thủy. Sẽ là sai lầm nghiêm trọng, khi xem những người chể tác rìu tay là đại diện cho khu vực năng động, tiên tiến, còn chế tác chopper chopping là đại diện cho khu vực bảo thủ và lạc hậu.

Với các địa điểm sơ kỳ Đá cũ hiện biết, phát hiện được trong vùng đồi gò thung lũng An Khê là bằng chứng về sự hiện diện của cộng đồng người giai đoạn tối cổ của nhân loại trên đất nước Việt Nam. Với những phát hiện này, chúng ta đã bổ sung thêm thung lũng $\mathrm{An}$ Khê (Việt Nam) vào bản đồ ra đời và quá trình tiến hóa của nhân loại trên thế giới (Hình 6).

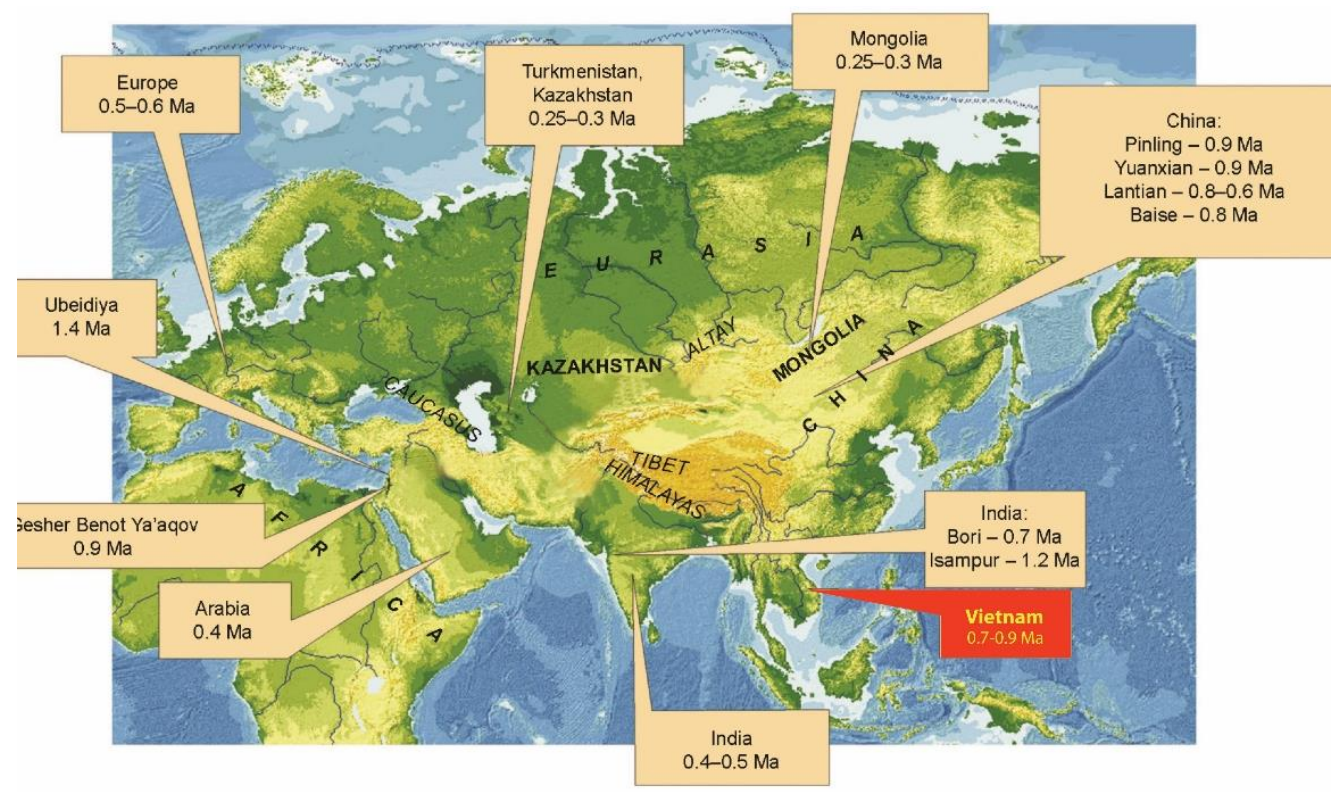

An Khê, Việt Nam trong bản đồ sơ kỳ Đá cũ lục địa Âu-Á

An Khe, Vietnam in the map of the Lower Paleolithical sites of the Eurasia

\section{Hình 6. Phân bố kỹ nghệ rìu tay ở Châu Á}

Nguồn: Derevianko và ctg. (2016).

\section{TÀI LIỆU THAM KHẢO}

Balout, L. (1967). Procédés d'analyse et questions de terminologie dans l'étude des ensembles industriels du Paléolithique inférieur en Afrique du Nord. In W. W. Bishop \& J. D. Clark (Eds.), Background to evolution in Africa (pp. 701-735). Chicago, USA: The University of Chicago Press.

Derevianko, A. P., Nguyen, G. D., Nguyen, K. S., Gladyshev, S. A., \& Kandyba, A. V. (2018). The tools of the Ankhe early paleolithic industry, Vietnam. In A. P. 
Derevianko (Eds), Paleoenvironment - The stone Age (pp. 300-315). Moscow, Russia: Siberian Branch of the Russian Academy of Sciences.

Derevianko, A. P., Nguyen, K. S., Tsybankov, A. A., \& Nguyen, G. D. (2016). The origin of bifacial industry in East and Southeast Asia. Novosibirsk, Russia: IAET SB RAS Publishing.

Gao, X., Huang, W., Hao, X., \& Chen, B. (1997). Fisson track dating of ancient man site Baise, China, and its significance in apace research, paleomagnetism and stratigraphy. Radiation measurements, 28(1-6), 565-570.

Guangmao, X. (2002). A discussion on hand axes from Baise. Acta Anthropologica Sinica, (21), 65-73.

Guangmao, X. (2007). Les industries paleolithiques de basin de Bose (Chine de Sud). L'Anthropologie, (111), 182-206.

Movius, H. (1948). The lower palaeolithic cultures of Southern and Eastern Asia, in transactions of the American philasophical society. New Ser, 38(4), 330-420.

Movius, H. (1949). New palaeolithic cultures of Southern and Eastern Asia. Philadelphia, USA: Philadelphia Press.

Movius, H. (1956). New palaeolithic sites, near Ting T'sun the Fen river, Shansi province, North China. Quaternaria, (3), 13-26.

Movius, H. (1958). Southern and Eastern Asia: Conclussion, in early palaeolithic in Southern and Eastern Asia. In F. Ikawa-Smith (Eds), Hague (pp. 351-355). Chicago, USA: Mouton Publishers.

Nguyen, K. S. (2017). Early paleolithic industry of Ankhe and primitive period in Vietnam. Vietnam Archaeology, (12), 13-25.

Nguyễn, K. S., \& Nguyễn, G. D. (2015). Hệ thống các di tích Đá cũ khu vực thượng du sông Ba. Tạp chí Khảo cổ học, (1), 7-19.

Nguyễn, K. S. (2017). Kỹ nghệ sơ kỳ Đá cũ An Khê với thời kỳ nguyên thủy Việt Nam. Tạp chí Khoa họ Xã hội Việt Nam, (4), 2-14.

Yiamei, H., Pottes, R., Baoyin, Y., Zhentang, G., Deino, A., Wei, W., Clark, J., Guangmao, X., \& Weiwen, H. (2000). Mid-Pleistocene acheuliean - like stone technology of the Bose Basin, Southern China. Science, 287(5458), 1622-1626. 